\title{
NHL expansion and fan allegiance: a mathematical modelling study
}

\author{
Jennifer Light ${ }^{1}$, Alina Chernin ${ }^{1}$ and Jane M. Heffernan ${ }^{1,2^{*}}$
}

\author{
*Correspondence: \\ jmheffer@yorku.ca \\ ${ }^{1}$ Department of Mathematics and \\ Statistics, York University, Toronto, \\ Canada \\ ${ }^{2}$ Centre for Disease Modelling, York \\ University, Toronto, Canada
}

\begin{abstract}
Expansion of the NHL hockey league is of current interest. Success of an expansion team will rely on approved geographic locations, and most importantly fan support. Fan allegiance can be likened to infectious disease transmission, whereby individuals are susceptible, infected and recovered from a current team's hockey season. We employ an infectious disease model to assess the viability of certain Canadian and American cities that have been discussed as potential locations for NHL expansion in the past decade. We find that Quebec City presents an ideal location for expansion, where as, Las Vegas is suboptimal.
\end{abstract}

\section{Introduction}

Expansion of the National Hockey League (NHL) has been a major conversation topic of team owners, players and fans over the past decade [3, 26, 31, 34]. Many cities in Canada and the USA have been featured in local and national media outlets as potential locations. Expansion to add another team to the Greater Toronto Area has been discussed widely $[3,16]$, as well as expansions to Las Vegas, Seattle and Kansas City (among others) [3]. The 2011 relocation of the Atlanta Thrashers to Winnipeg (the team was renamed the Winnipeg Jets, a team that had been moved out of Winnipeg in the year 1996 to become the Phoenix Coyotes) has also led to speculation that Quebec City, a city that lost its NHL team in 1995 (the Quebec Nordiques were moved to form the Colorado Avalanche), could provide an ideal location for relocation or expansion [26].

Success of a new NHL team will depend on the locational quality of a city or geographic region that will be able to support a team through thick and thin. Currently, several existing NHL teams are struggling financially, which may be attributed to poor performance. However, it is possible for a team to struggle financially, despite performing well on the ice. For example, while NHL teams in Canada and the northeastern United States have fairly steady revenues, teams in the southern US regularly rank in the bottom of league revenue and attendance lists [7-11, 21-24, 29] - hockey may not be of interest to individuals living in cities in the sun-belt. Poor performance and poor locational quality simply lead to a lack of fans. NHL teams rely heavily on fan support to bring in revenue from ticket sales and merchandise purchases (note that the NHL is much more heavily reliant on its gate revenue than the NFL because of significantly less lucrative national television deals $[2,5,19])$. Thus fan allegiance is needed for an NHL team to ultimately survive. 
We propose that the spread of fan allegiance can be likened to transmission of an infectious disease. An individual can be 'infected' through contact with fans in the population - typically due to the influence of family or friends, but individuals may also lose interest and recover or become immune to all future exposures. Also, in situations where there are multiple teams close by, a multi-strain model of infectious disease spread can be considered. We thus present a mathematical modelling study of fan allegiance using an infectious disease dynamical system. The model is then used to assess locations in Canada and the USA where NHL expansion may be successful.

In the sections that follow, we apply a Susceptible-Infected-Recovered modelling framework of fan allegiance so as to evaluate the locational quality of cities interested in housing new (or relocated) NHL teams. Model parameters are defined by the location attributes that have been shown to affect team financial success $[17,18]$. The Basic Reproductive Ratio $\left(\mathcal{R}_{0}\right)$, the number of new fans produced by one fan that is introduced into a totally susceptible population, is determined. Locations associated with $\mathcal{R}_{0}$ values greater than unity are deemed acceptable for NHL expansion.

Note that in the course of this work, the NHL announced a bidding process for expansion [32]. Two cities filed applications: Quebec City and Las Vegas [30]. These cities were previously included in our analysis, so no modifications to the modelling study were needed.

\section{Methods}

Model

We propose that fan allegiance to a sports team spreads mainly through contact with other fans. As a result, it is appropriate to use an epidemiological model to explain the transmission of fan allegiance in the NHL.

\section{Standard SIR model}

The basic Susceptible-Infected-Recovered model of infectious disease dynamics is given by:

$$
\begin{aligned}
\dot{S} & =-\beta S I \\
\dot{I} & =\beta S I-\gamma I \\
\dot{R} & =\gamma I \\
N & =S+I+R
\end{aligned}
$$

with the basic reproductive ratio:

$$
R_{0}=\frac{\beta N}{\gamma}
$$

Here, $\beta>0$ represents the mean transmission rate of the disease, and $1 / \gamma, \gamma>0$ represents the mean infectious period. It should be noted that for $S, I$, and $R$ to represent proportions of the population, we set $N=1$ in the last equation.

\section{Expanding the model}

In a 2014 survey, The Forum Poll asked respondents in Canada to rate their dedication to NHL hockey as 'part-time,' 'regular,' 'enthusiastic', or 'extreme' [13]. Combining the parttime and regular fans in one group, and the enthusiastic and extreme fans in another, we expanded the classic SIR model to include a chronically infected compartment $(C)$. 
Essentially, once a person is infected by the 'disease' of fan allegiance, it is possible for this infected person to become a chronic fan of one team, beyond recovery. This compartment represents enthusiastic and extreme fans who are very devoted to their respective teams of choice and are unlikely to recover from this 'disease'.

The National Hockey League includes thirty teams, each of which draws fans at varying rates. For most NHL teams there exists little to no competition for fan allegiance among locals, as most teams are located far from each other geographically, in different and distinct cites. In New York City and Los Angeles the situation is different, however, with the LA Kings and Anaheim Ducks less than $100 \mathrm{~km}$ from each other, and the NY Rangers, NY Islanders and NJ Devils residing within a $50 \mathrm{~km}$ radius. We thus expand the model to consider one, two or three teams so that competition for fans can be realized. In the case of two teams the model is as follows:

$$
\begin{aligned}
\dot{S} & =-S\left[\beta_{1}\left(I_{1}+C_{1}\right)+\beta_{2}\left(I_{2}+C_{2}\right)\right] \\
\dot{I}_{1} & =\beta_{1} S\left(I_{1}+C_{1}\right)-\gamma I_{1}-\alpha_{1} I_{1}+\delta_{21}\left[\left(I_{1}+C_{1}\right) I_{2}\right]-\delta_{12}\left[I_{1}\left(I_{2}+C_{2}\right)\right] \\
\dot{I}_{2} & =\beta_{2} S\left(I_{2}+C_{2}\right)-\gamma I_{2}-\alpha_{2} I_{2}+\delta_{12}\left[I_{1}\left(I_{2}+C_{2}\right)\right]-\delta_{21}\left[\left(I_{1}+C_{1}\right) I_{2}\right] \\
\dot{C}_{1} & =\alpha_{1} C_{1} \\
\dot{C}_{2} & =\alpha_{2} C_{2} \\
\dot{R} & =\gamma\left(I_{1}+I_{2}\right) \\
N & =S+I_{1}+I_{2}+C_{1}+C_{2}+R
\end{aligned}
$$

where $N$ is the total number of susceptible individuals at the time an NHL expansion team is located in the geographic region of the city. A schematic of the model is provided in Fig. 1. Briefly, $\beta$ and $\gamma$ are as above; $\alpha$ represents the mean rate at which infection becomes chronic (i.e. the rate of movement from compartment $I$ to compartment $C$ ); and $\delta$ represents the mean rate at which an individual infected with strain $i$ becomes infected with strain $j$ instead (i.e. 'switches' teams).

At the time of expansion it is expected that there will be no chronically infected individuals in the population, and that switching between teams will be negligible. Therefore, we can determine that the basic reproductive ratio of a new team in a geographic region will be given by

$$
R_{0}=\frac{\beta N}{\gamma}
$$

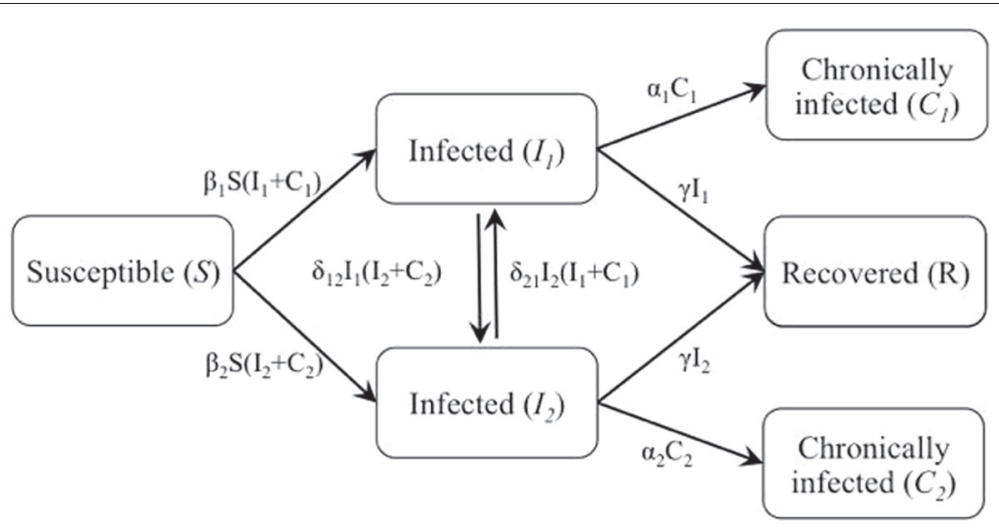

Fig. 1 Flow diagram 
Note that demographics (birth and death) are ignored here. This permits the study of $\mathcal{R}_{0}$ for one NHL season.

\section{Parameters}

The mean rate of transmission of infection for team $t, \beta_{t}$, has several influencing factors. Firstly, team success is an important factor in fan allegiance since successful teams attract more fans, as seen during the 2015 playoff run of the Toronto Blue Jays [4]. Secondly, a team's physical location may affect its ability to attract fans for several reasons: a city with a larger population means there are more potential fans nearby; the average income of the population has an effect; and because hockey is a winter sport, cities with colder climates have more inhabitants who are hockey fans. We propose that the last reason holds because in colder climates, inhabitants of the city are more likely to play the sport themselves, whether casually or in an organized league. It is worth mentioning that many children in Canada and the northeastern United States grow up playing shinny hockey in winter and road hockey in summer. We suggest that this early interest in the sport often leads to following an NHL team in adulthood.

Finally, following professional sports leagues tends to be a social phenomenon [15]: most hockey fans have either played the sport themselves or have been influenced by family and friends to become a fan. Thus, a susceptible individual's social environment - their friends, family, and coworkers - is an important factor in determining the rate at which individuals become a fan of an NHL team. An individual whose social environment includes few hockey fans will be much less likely to become 'infected' than an individual whose close family and friends are 'chronic' hockey fans.

In order to take team success into account in determination of $\beta$, we focused on success in the NHL's post-season. Called the Stanley Cup playoffs, the post-season consists of four rounds, each a best-of-seven-games series. Many NHL players readily admit that winning the Stanley Cup is the only important type of success (e.g., "I can't hear what Jeremy says, because I've got my two Stanley Cup rings plugging my ears." - Patrick Roy, four-time Stanley Cup winning NHL goaltender from 1985 to 2003, in response to a comment made by Jeremy Roenick, NHL forward from 1988 to 2009, during the 1996 NHL playoffs. (Roenick did not win a Cup during his career)). We considered only the seasons from $2000-01^{1}$ to $2014-15$, the most recent completed season. ${ }^{2}$

However, since only one Stanley Cup is awarded for each season, there is simply not enough data to draw meaningful conclusions. We considered separately either playoff series wins or playoff series appearances (which includes series won and lost), but neither of these metrics gives a complete picture on its own. Any useful measurement of team success rates must take into account Stanley Cup wins, playoff series wins, and also playoff series appearances (see Table 1 and Fig. 2). Simply adding the number of Cup wins, series wins, and series appearances, however, will also not suffice, since appearances should not influence fans as much as wins, and playoff wins will not influence fans as much as Stanley Cup championships. Also, such simple addition may rank teams with more Stanley Cups lower than a team with less Cups, but more playoff appearances (e.g., Chicago and Detroit, Fig. 2). 
Table 1 Revenue and playoff success for teams in the NHL

\begin{tabular}{|c|c|c|c|c|}
\hline \multicolumn{5}{|c|}{ Financial and on-ice success of NHL teams } \\
\hline Team & Revenue $^{a}$ & Playoff appearances ${ }^{b}$ & Playoff wins ${ }^{c}$ & Stanley cup wins ${ }^{d}$ \\
\hline Anaheim ducks & 107 & 21 & 13 & 1 \\
\hline Arizona coyotes & 80 & 6 & 2 & 0 \\
\hline Boston bruins & 164 & 19 & 10 & 1 \\
\hline Buffalo sabres & 103 & 10 & 5 & 0 \\
\hline Calgary flames & 122 & 10 & 4 & 0 \\
\hline Carolina hurricanes & 91 & 12 & 9 & 1 \\
\hline Chicago blackhawks & 172 & 22 & 16 & 3 \\
\hline Colorado avalanche & 104 & 16 & 9 & 1 \\
\hline Columbus blue Jackets & 86 & 2 & 0 & 0 \\
\hline Dallas stars & 113 & 11 & 4 & 0 \\
\hline Detroit red wings & 134 & 29 & 17 & 2 \\
\hline Edmonton oilers & 119 & 6 & 3 & 0 \\
\hline Florida panthers & 83 & 2 & 0 & 0 \\
\hline Los Angeles kings & 146 & 16 & 11 & 2 \\
\hline Minnesota wild & 111 & 10 & 4 & 0 \\
\hline Montreal canadiens & 187 & 18 & 8 & 0 \\
\hline Nashville predators & 98 & 10 & 2 & 0 \\
\hline New Jersey devils & 111 & 21 & 12 & 1 \\
\hline New York islanders & 83 & 6 & 0 & 0 \\
\hline New York rangers & 217 & 19 & 10 & 0 \\
\hline Ottawa senators & 117 & 18 & 8 & 0 \\
\hline Philadelphia flyers & 136 & 21 & 10 & 0 \\
\hline Pittsburgh penguins & 141 & 22 & 13 & 1 \\
\hline St. Louis blues & 98 & 13 & 4 & 0 \\
\hline San Jose sharks & 117 & 23 & 11 & 0 \\
\hline Tampa Bay lightning & 97 & 16 & 10 & 1 \\
\hline Toronto maple leafs & 190 & 9 & 4 & 0 \\
\hline Vancouver canucks & 154 & 18 & 7 & 0 \\
\hline Washington capitals & 117 & 13 & 4 & 0 \\
\hline Winnipeg jets ${ }^{\mathrm{e}}$ & 102 & 1 & 0 & 0 \\
\hline Mean & 123.00 & 14.03 & 7.00 & 0.47 \\
\hline
\end{tabular}

Notes: ain millions of USD, for the 2013-2014 season [24]; b Playoff series appeared in, 2001-2015 [14]; ' Playoff series won,

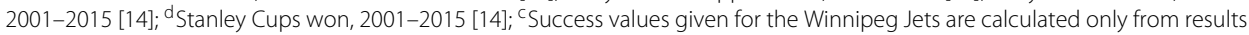
obtained since the franchise moved to Winnipeg for the 2011-12 season

We therefore propose $S_{t}$ as the weighted per-season success rating of team $t$ for the seasons 2000-01 to 2014-15, given by

$$
S_{t}=\frac{a \cdot P S A+b \cdot P S W+c \cdot S C}{N},
$$

where $N=14$ is the number of seasons in our analysis, $S C$ represents Stanley Cup wins, $S W$ is playoff series wins in any round, $S A$ is playoff series appearances; and the coefficients $a, b, c$ give the relative significance or 'weight' of each type of success, as follows:

- a: Of the thirty teams in the NHL, sixteen play in the first round of the playoffs each season, so that each of these teams gains one playoff series appearance. Thus, $a=\frac{30}{16}=1.875$. 


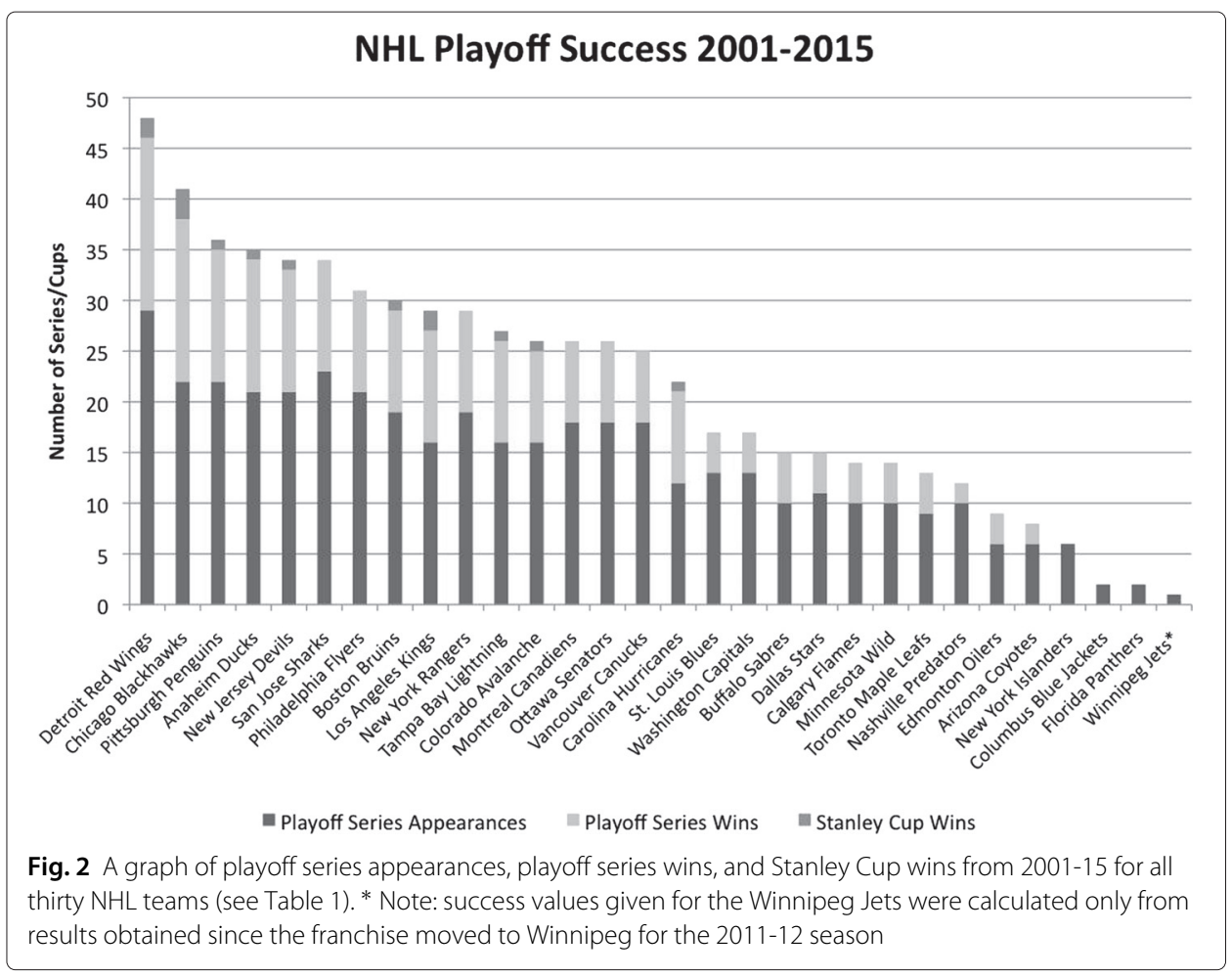

- $b$ : Half of the teams in the first round of the playoffs win their respective series. Thus $b=2 \cdot \frac{30}{16}=3.75$, which is twice the value of a.

- c: Only one NHL team wins the Stanley Cup each season, so we take $c=\frac{30}{1}=30$.

For comparison between teams the $S_{t}$ values are divided by the mean team success rate $\mu_{S_{t}}$ to obtain

$$
s_{t}=\frac{S_{t}}{\mu_{S_{t}}} .
$$

Table 2 lists the success ratings for all thirty NHL teams using the Stanley Cup playoff data provided in Appendix: Table 1. Chicago is ranked first in the league with three Stanley Cup wins in the last 14 years, followed by Detroit and then Los Angeles, each with two championships.

To quantify the second influencing factor, team location, we slightly modified part of a statistical model given in Jones and Ferguson [18] that defined $H_{t}$, the locational quality of team $t$ 's home city, as a function of the city population size, mean income, and country. Jones and Ferguson defined $H_{t}$ as:

$$
H_{t}=\frac{1}{4} \frac{a_{t}^{2}}{b_{t}^{2}}
$$

and

$$
\begin{aligned}
& \log a_{t}=\alpha_{0}+\alpha_{1} C A N+\alpha_{2} \log P O P+\alpha_{3} \log I N C \\
& \log b_{t}=\beta_{0}+\beta_{1} C A N+\beta_{2} \log P O P+\beta_{3} \log I N C
\end{aligned}
$$

where $C A N$ is a dummy variable with a value of 1 if the team is located in Canada and zero otherwise, $P O P$ is the city's population, and INC is the mean income in the city. Before 
Table 2 Success ratings for teams in the NHL

\begin{tabular}{|c|c|c|}
\hline \multicolumn{3}{|c|}{ Success ratings of NHL teams } \\
\hline Team & $S_{t}{ }^{a}$ & $s_{t}{ }^{\mathrm{b}}$ \\
\hline Anaheim ducks & 8.4375 & 1.7722 \\
\hline Arizona coyotes & 1.3393 & 0.2813 \\
\hline Boston bruins & 7.3661 & 1.5471 \\
\hline Buffalo sabres & 2.6786 & 0.5626 \\
\hline Calgary flames & 2.4107 & 0.5063 \\
\hline Carolina hurricanes & 6.1607 & 1.2940 \\
\hline Chicago blackhawks & 13.6607 & 2.8692 \\
\hline Colorado avalanche & 6.6964 & 1.4065 \\
\hline Columbus blue jackets & 0.2679 & 0.0563 \\
\hline Dallas stars & 2.5446 & 0.5345 \\
\hline Detroit red wings & 12.7232 & 2.6723 \\
\hline Edmonton oilers & 1.6071 & 0.3376 \\
\hline Florida panthers & 0.2679 & 0.0563 \\
\hline Los Angeles kings & 9.3750 & 1.9691 \\
\hline Minnesota wild & 2.4107 & 0.5063 \\
\hline Montreal canadiens & 4.5536 & 0.9564 \\
\hline Nashville predators & 1.8750 & 0.3938 \\
\hline New Jersey devils & 8.1696 & 1.7159 \\
\hline New York islanders & 0.8036 & 0.1688 \\
\hline New York rangers & 5.2232 & 1.0970 \\
\hline Ottawa senators & 4.5536 & 0.9564 \\
\hline Philadelphia flyers & 5.4911 & 1.1533 \\
\hline Pittsburgh penguins & 8.5714 & 1.8003 \\
\hline St. Louis blues & 2.8125 & 0.5907 \\
\hline San Jose sharks & 6.0268 & 1.2658 \\
\hline Tampa bay lightning & 6.9643 & 1.4627 \\
\hline Toronto maple leafs & 2.2768 & 0.4782 \\
\hline Vancouver canucks & 4.2857 & 0.9001 \\
\hline Washington capitals & 2.8125 & 0.5907 \\
\hline Winnipeg jets ${ }^{c}$ & 0.4688 & 0.0985 \\
\hline Mean & 4.7612 & 1.0000 \\
\hline
\end{tabular}

Notes: a'See Table 1 and Eq. (8); bSee Eq. (9); ' Success values given for the Winnipeg Jets are calculated only from results obtained since the franchise moved to Winnipeg for the 2011-12 season

applying the model in Jones and Ferguson to the thirty current NHL teams using current data, we first made one modification to the $C A N$ variable. After looking at climate data for all current NHL cities [6], we chose to give a value of 1 for this variable to cities with climates similar to those in Canadian cities. We considered the average high temperature for each city's coldest month; in Vancouver, the mildest of the Canadian cities with an NHL team, this temperature is $6^{\circ} \mathrm{C}$. We took this value as our benchmark so that any team whose city had a coldest month average high temperature of $6^{\circ} \mathrm{C}$ or less was given a $C A N$ value of 1 . We therefore changed the variable name from CAN to WINT. Parameter values $a_{t}$ and $b_{t}$ are listed in Table 3. Note that we used gross domestic product per capita as an approximation of income per capita, all in USD. The final modification made to the Jones and Ferguson model was to again normalize the locational qualities to obtain a mean value of 1 , defining:

$$
h_{t}=\frac{H_{t}}{\mu_{H_{t}}}
$$


Table 3 Locational qualities for teams in the NHL and selected other North American cities

\begin{tabular}{|c|c|c|c|c|c|c|c|c|}
\hline \multicolumn{9}{|c|}{ Locational qualities of NHL teams and selected other North American cities } \\
\hline Team or City & Population (millions) ${ }^{a}$ & GDP per capita ${ }^{a}$ & Mean cold temp ${ }^{b}$ & WINTC & $a_{t}{ }^{d}$ & $b_{t}{ }^{\mathrm{e}}$ & $H_{t}^{f}$ & $h_{t}{ }^{\mathrm{g}}$ \\
\hline Anaheim ducks & 5.552807 & $\$ 65,052.00$ & 21 & 0.00 & 23872.2091 & 1256.5751 & 90.2294 & 0.7639 \\
\hline Arizona coyotes & 4.459692 & $\$ 46,430.00$ & 20 & 0.00 & 26569.6757 & 1330.5856 & 99.6843 & 0.8439 \\
\hline Boston bruins & 4.725601 & $\$ 76,204.00$ & 2 & 1.00 & 27631.2531 & 1251.2492 & 121.9140 & 1.0321 \\
\hline Buffalo sabres & 1.133666 & $\$ 64,090.00$ & 0 & 1.00 & 25899.9405 & 1241.9735 & 108.7209 & 0.9204 \\
\hline Calgary flames & 1.401800 & $\$ 69,826.00$ & -1 & 1.00 & 25566.3899 & 1229.4164 & 108.1137 & 0.9153 \\
\hline Carolina hurricanes & 1.244021 & $\$ 51,729.00$ & 11 & 0.00 & 22711.8760 & 1258.0512 & 81.4797 & 0.6898 \\
\hline Chicago blackhawks & 9.568133 & $\$ 58,861.00$ & -1 & 1.00 & 32472.5174 & 1339.6617 & 146.8864 & 1.2435 \\
\hline Colorado avalanche & 2.746768 & $\$ 61,795.00$ & 6 & 1.00 & 28460.1760 & 1281.8863 & 123.2299 & 1.0432 \\
\hline Columbus blue jackets & 1.988002 & $\$ 54,780.00$ & 3 & 1.00 & 28918.0283 & 1299.4250 & 123.8155 & 1.0482 \\
\hline Dallas stars & 6.937652 & $\$ 59,483.00$ & 14 & 0.00 & 25195.9012 & 1285.8766 & 95.9845 & 0.8126 \\
\hline Detroit red wings & 4.286134 & $\$ 48,421.00$ & 0 & 1.00 & 32487.1820 & 1358.8221 & 142.9022 & 1.2098 \\
\hline Edmonton oilers & 1.320300 & $\$ 62,832.00$ & -6 & 1.00 & 26458.4329 & 1251.9393 & 111.6611 & 0.9453 \\
\hline Florida panthers & 5.905918 & $\$ 44,480.00$ & 25 & 0.00 & 27701.5572 & 1351.9469 & 104.9613 & 0.8886 \\
\hline Los Angeles kings & 7.668163 & $\$ 65,052.00$ & 20 & 0.00 & 24583.7917 & 1267.9831 & 93.9747 & 0.7956 \\
\hline Minnesota wild & 3.491620 & $\$ 60,544.00$ & -5 & 1.00 & 29313.3379 & 1295.4964 & 127.9965 & 1.0836 \\
\hline Montreal canadiens & 4.011200 & $\$ 38,867.00$ & -5 & 1.00 & 35078.3776 & 1413.4876 & 153.9696 & 1.3035 \\
\hline Nashville predators & 1.785349 & $\$ 53,193.00$ & 8 & 0.00 & 23225.5464 & 1264.1947 & 84.3809 & 0.7143 \\
\hline New Jersey devils & 5.419961 & $\$ 69,915.00$ & 4 & 1.00 & 28900.5599 & 1276.5556 & 128.1366 & 1.0848 \\
\hline New York islanders & 4.014786 & $\$ 69,915.00$ & 4 & 1.00 & 28121.9798 & 1265.8737 & 123.3818 & 1.0445 \\
\hline New York rangers & 10.639183 & $\$ 69,915.00$ & 4 & 1.00 & 30729.9067 & 1300.8921 & 139.5018 & 1.1810 \\
\hline Ottawa senators & 1.318400 & $\$ 44,149.00$ & -6 & 1.00 & 30215.1591 & 1337.7141 & 127.5449 & 1.0798 \\
\hline Philadelphia flyers & 6.060560 & $\$ 57,166.00$ & 5 & 1.00 & 31495.4880 & 1329.9238 & 140.2113 & 1.1870 \\
\hline Pittsburgh penguins & 2.361681 & $\$ 58,615.00$ & 2 & 1.00 & 28635.7681 & 1289.2109 & 123.3417 & 1.0442 \\
\hline San Jose sharks & 1.945539 & $\$ 82,414.00$ & 14 & 0.00 & 19849.6403 & 1167.1598 & 72.3077 & 0.6121 \\
\hline St. Louis blues & 2.807760 & $\$ 50,070.00$ & 4 & 1.00 & 30868.6490 & 1334.4001 & 133.7837 & 1.1326 \\
\hline Tampa Bay lightning & 2.895946 & $\$ 44,999.00$ & 21 & 0.00 & 25848.9340 & 1322.3520 & 95.5281 & 0.8087 \\
\hline
\end{tabular}


Table 3 Locational qualities for teams in the NHL and selected other North American cities (Continued)

\begin{tabular}{|c|c|c|c|c|c|c|c|c|}
\hline Toronto maple leafs & 6.036800 & $\$ 45,771.00$ & -1 & 1.00 & 34233.6201 & 1386.5012 & 152.4071 & 1.2902 \\
\hline Vancouver canucks & 2.476600 & $\$ 44,337.00$ & 6 & 1.00 & 31948.2055 & 1360.4518 & 137.8690 & 1.1672 \\
\hline Washington capitals & 6.056296 & $\$ 73,017.00$ & 6 & 1.00 & 28720.5782 & 1270.1267 & 127.8298 & 1.0822 \\
\hline Winnipeg jets & 0.778500 & $\$ 41,719.00$ & -11 & 1.00 & 29421.4851 & 1332.2235 & 121.9312 & 1.0322 \\
\hline Hamilton & 0.765228 & $\$ 35,315.00$ & -1 & 1.00 & 31278.1681 & 1373.9382 & 129.5652 & 1.0969 \\
\hline Kansas City & 2.070981 & $\$ 51,157.00$ & 4 & 1.00 & 29783.5302 & 1317.7477 & 127.7109 & 1.0812 \\
\hline Las Vegas & 2.051796 & $\$ 45,744.00$ & 14 & 0.00 & 24896.4995 & 1305.6199 & 90.9040 & 0.7696 \\
\hline Québec city & 0.797500 & $\$ 41,907.00$ & -7 & 1.00 & 29436.2287 & 1331.9975 & 122.0949 & 1.0336 \\
\hline Seattle & 3.663399 & $\$ 73,012.00$ & 8 & 0.00 & 22007.7246 & 1215.3763 & 81.9726 & 0.6940 \\
\hline MEAN (NHL teams) & 4.034628 & $\$ 57,788.03$ & 5.47 & 0.700 & 28171.2056 & 1298.3985 & 118.1226 & 1.0000 \\
\hline
\end{tabular}


where $\mu_{H_{t}}$ is the mean locational quality for all thirty NHL teams. The locational quality for all thirty NHL teams is shown in Table 3 and Fig. 3. It is also shown for the five expansion cities being considered. It is interesting to note that little correlation exists between the city population size and the locational quality.

We now need to quantify the final influencing factor, namely the effect of an individual's social environment on their susceptibility to becoming a fan of an NHL team. Defining $p$ as the 'rating' of an individual's social environment, we chose three representative values in order to simplify our model, as follows:

1. $p=0.05$ represents a scenario where a susceptible person does not have any close friends or family who are hockey fans and does not play hockey at any level, on any surface.

2. $p=0.25$ represents a scenario where a susceptible person has some friends or family who are regular fans (i.e. they belong to class $I_{t}$ for team $t$ )

3. $p=0.75$ represents a scenario where a susceptible person's close friends or family are devoted fans (i.e. they belong to class $C_{t}$ for team $t$ )

Bringing the three influencing factors together, we now define

$$
\beta_{t}=p s_{t} h_{t}
$$

Other model parameters are easier to determine. We set the mean infectious period, $1 / \gamma$, at 9 months, the length of a typical NHL season including playoffs (approximately October through June). According to The Forum Poll [13], approximately $30 \%$ of hockey fans are 'enthusiastic' or 'extreme' fans, combined. Thus, $\alpha$ could be calibrated so that $30 \%$ of NHL teams are chronically infected. However, a casual fan is more likely to become chronically infected by fan allegiance to a well-located, winning team, and therefore $\alpha$ must also depend on locational quality and success rates. We thus assume that $\alpha$ is proportional to $\beta$, which is very small when $\beta$ is small, properly reflecting that fact that the rate of becoming a chronically infected fan of a team will be very small (and may be almost

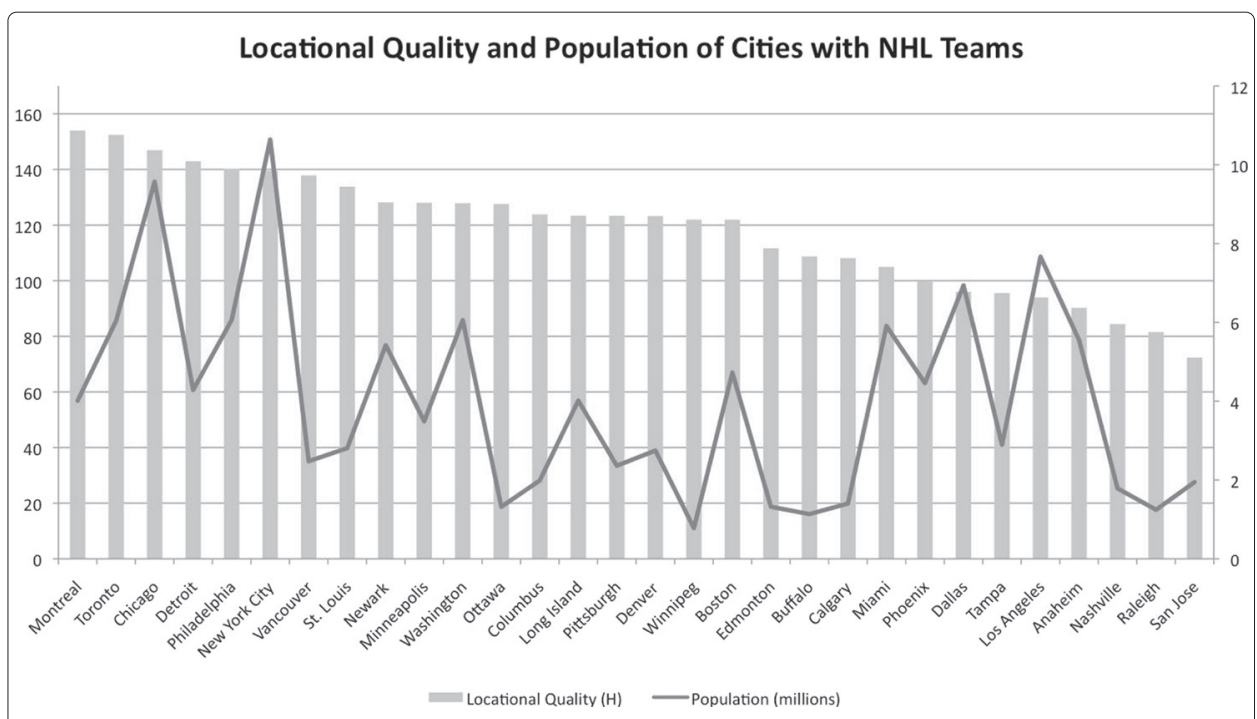

Fig. 3 Locational quality. The calculated locational quality for the thirty NHL team host cities is shown 
zero) for expansion teams, especially in their first season. For the purposes of this study, we set $\alpha=0.3 \beta$.

Though not relevant to the results below, for the sake of thoroughness we will define $\delta_{t_{1} t_{2}}$, the mean rate of 'switching' allegiance from team $t_{1}$ to team $t_{2}$. Switching team allegiance is not a common phenomenon. We suggest that it happens mainly among casual fans (class $I$ ), and that it depends on an individual's social environment as well as on the success ratings of both the 'old' and 'new' teams. We further propose that this 'switching' only occurs when the new team's success rating is higher than that of the old team. We therefore define $\delta_{t_{1} t_{2}}$

$$
\delta_{t_{1} t_{2}}= \begin{cases}p \cdot\left(s_{t_{2}}-s_{t_{1}}\right) / \mu_{s_{t}} & \text { if } s_{t_{2}}>s_{t_{1}} \\ 0 & \text { otherwise }\end{cases}
$$

\section{Results}

The equilibria of Eq. (6) correspond to an uninfected equilibrium $E_{0}=\{S, 0,0,0,0, N-S\}$ and an infected equilibrium $E_{1}=\left\{0,0,0, C_{1}, C_{2}, N-C 1-C 2\right\}$. However, over one NHL season $E_{1}$ cannot be achieved, and thus every season ends with a population distribution across all compartments $S, I_{1}, I_{2}, C_{1}, C_{2}, R$; it is assumed that over the course of the summer the casually infected individuals may wane back to the susceptible class $S$. It is now possible to determine the circumstances under which a given team's fanbase is likely to grow; in other words, when the 'infection' will spread. This corresponds to determining the point at which $\mathcal{R}_{0}>1$ in an epidemiological model. Here,

$$
\mathcal{R}_{0, t}=\frac{\beta_{t} S}{\gamma}=\frac{p h_{t} s_{t} S}{\gamma}
$$

$\mathcal{R}_{0}$ has a useful predictive property whereby we can expect that an infection will spread in a population only when $\mathcal{R}_{0}>1$. We will utilize this property of $\mathcal{R}_{0}$ in order to investigate the ability of different NHL teams to grow their respective fanbases.

It is important to note that once the chronically infected compartment is populated, $E_{1}$ is always stable, since chronically infected fans will always infect others in the population. This, however, does not imply that a team will be financially viable, since a small number of chronically infected fans will not be able to support a team financially (through merchandise purchases and ticket sales). The chronically infected compartment must reach a threshold level for this to be true. Determination of this threshold is beyond the scope of this study. We are providing a first step towards this calculation, determining geographical locations where 'infection' will spread.

\section{Current NHL teams}

First, we look at the current NHL teams to determine $\mathcal{R}_{0}$ with different success rates, and different locational qualities. Table 4 lists the $\mathcal{R}_{0}$ values for all NHL teams when $p=0.05$, 0.25 , and 0.75 . The $\mathcal{R}_{0}$ values are also shown in Fig. 4. 
Table 4 Basic reproduction ratios for teams in the NHL, calculated for $p=0.05,0.25$, and 0.75

\begin{tabular}{|c|c|c|c|}
\hline \multicolumn{4}{|c|}{$\mathcal{R}_{0}$ for $p=0.05, p=0.25, p=0.75$} \\
\hline Team & $\mathcal{R}_{0, p}=0.05$ & $\mathcal{R}_{0, p}=0.25$ & $\mathcal{R}_{0, p}=0.75$ \\
\hline Anaheim ducks & 0.6092 & 3.0458 & 9.1373 \\
\hline Arizona coyotes & 0.1068 & 0.5341 & 1.6024 \\
\hline Boston bruins & 0.7185 & 3.5927 & 10.7782 \\
\hline Buffalo sabres & 0.2330 & 1.1651 & 3.4952 \\
\hline Calgary flames & 0.2085 & 1.0427 & 3.1281 \\
\hline Carolina hurricanes & 0.4016 & 2.0082 & 6.0247 \\
\hline Chicago blackhawks & 1.6055 & 8.0277 & 24.0831 \\
\hline Colorado avalanche & 0.6603 & 3.3014 & 9.9041 \\
\hline Columbus blue jackets & 0.0265 & 0.1327 & 0.3980 \\
\hline Dallas stars & 0.1954 & 0.9772 & 2.9315 \\
\hline Detroit red wings & 1.4548 & 7.2740 & 21.8219 \\
\hline Edmonton oilers & 0.1436 & 0.7179 & 2.1538 \\
\hline Florida panthers & 0.0225 & 0.1125 & 0.3374 \\
\hline Los Angeles kings & 0.7049 & 3.5247 & 10.5740 \\
\hline Minnesota wild & 0.2469 & 1.2345 & 3.7034 \\
\hline Montreal canadiens & 0.5610 & 2.8049 & 8.4148 \\
\hline Nashville predators & 0.1266 & 0.6330 & 1.8989 \\
\hline New Jersey devils & 0.8376 & 4.1881 & 12.5642 \\
\hline New York islanders & 0.0793 & 0.3967 & 1.1900 \\
\hline New York rangers & 0.5830 & 2.9151 & 8.7453 \\
\hline Ottawa senators & 0.4647 & 2.3235 & 6.9706 \\
\hline Philadelphia flyers & 0.6160 & 3.0802 & 9.2406 \\
\hline Pittsburgh penguins & 0.8459 & 4.2296 & 12.6888 \\
\hline St. Louis blues & 0.3011 & 1.5053 & 4.5160 \\
\hline San Jose sharks & 0.3487 & 1.7434 & 5.2303 \\
\hline Tampa Bay lightning & 0.5323 & 2.6616 & 7.9848 \\
\hline Toronto maple leafs & 0.2776 & 1.3882 & 4.1647 \\
\hline Vancouver canucks & 0.4728 & 2.3639 & 7.0917 \\
\hline Washington capitals & 0.2877 & 1.4383 & 4.3150 \\
\hline Winnipeg jets & 0.0457 & 0.2287 & 0.6860 \\
\hline
\end{tabular}

As an example, consider the Chicago Blackhawks, 2015 Stanley Cup champions. The basic reproductive ratio in Chicago when $p=0.05$ is

$$
\begin{aligned}
\mathcal{R}_{0} & =9 \cdot 0.05 h_{\text {Chi }} s_{\text {Chi }} \\
& =0.45 \cdot 1.2435 \cdot 2.8692 \\
& =1.6055
\end{aligned}
$$

The Blackhawks have $\mathcal{R}_{0}>1$ even if $\mathrm{p}$ is small. Winners of three Stanley Cups since the 2004-05 lockout, the Blackhawks have the highest $\mathcal{R}_{0}$ values in the league. They are followed closely by the Detroit Red Wings, winners of two Cups since 2001. For all three $p$-values, both Chicago and Detroit have $\mathcal{R}_{0}>1$.

Three teams in the league, the Florida Panthers, Columbus Blue Jackets, and Winnipeg Jets, have $\mathcal{R}_{0}<1$ for all three values of $p$. This may be related to a warm geographic location (Florida), poor playoff success (Columbus), and the fact that a team is fairly new to the NHL (Winnipeg). A further five teams have $\mathcal{R}_{0}<1$ for $p \leq 0.25$ : the New York 


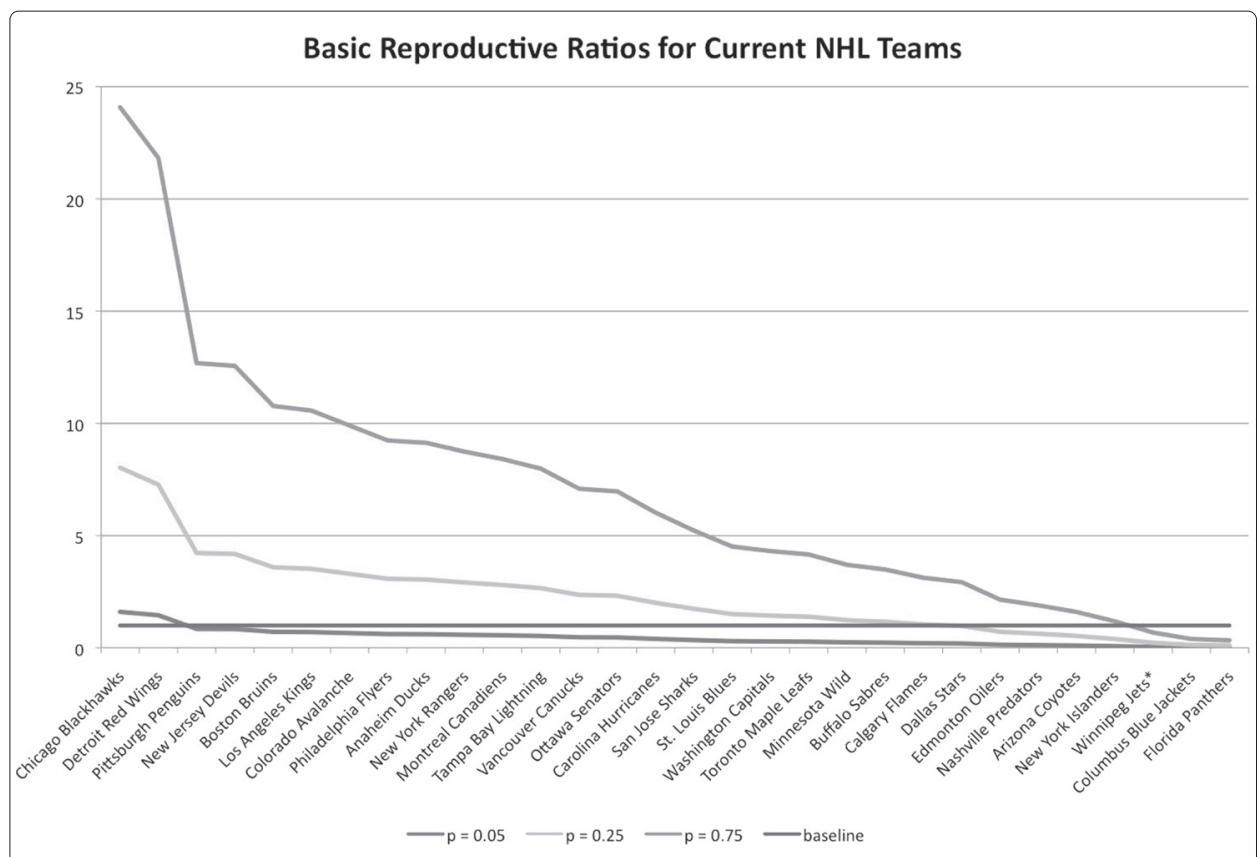

Fig. 4 Basic reproductive ratio $\mathcal{R}_{0}$. $\mathcal{R}_{0}$ is shown for all current NHL teams when $p=0.05,0.25,0.75$

Islanders, Arizona Coyotes, Nashville Predators, Edmonton Oilers, and Dallas Stars - all teams with few playoff appearances in the timeframe of reference. It is interesting to note that the Toronto Maple Leafs, despite having similar playoff appearances to these teams, have $\mathcal{R}_{0}>1$ when $p=0.25$.

Appendix: Figs. 5 and 6, show that a team's success rate has a much stronger effect on $\mathcal{R}_{0}$ than its locational quality. The outliers whose success rates are greater than their $\mathcal{R}_{0}$ values (Los Angeles, Anaheim, Tampa Bay, Carolina, San Jose, Dallas, and Nashville) all have locational qualities well below the league average, and the outliers whose success rates are lower than their $\mathcal{R}_{0}$ values all have high locational qualities. Thus locational quality does have an effect on $\mathcal{R}_{0}$, but this is small compared to team success. It is interesting to note that all the teams that have a lower success rate than their corresponding $\mathcal{R}_{0}$ are either Original Six teams, ${ }^{3}$ located in Canada, or have been in the NHL since the 1967-68 expansion.

Although the success rate is the most significant factor in determining a team's $\mathcal{R}_{0}$, a low locational quality is certainly a disadvantage for a team trying to grow its fanbase. Such a team requires a higher success rate to attract the same number of new fans compared to a team with a higher locational quality. According to this rationale, of the three teams that have $\mathcal{R}_{0}$ values below 1 for all values of $p$, the Florida Panthers need a higher success rate than the Columbus Blue Jackets and Winnipeg Jets in order to be viable. In order to attract fans in the $p=0.75$ category, Florida must increase its success rate to approximately 6 playoff series appearances in 14 years, meaning that the team needs to reach the playoffs nearly every second year. Columbus and Winnipeg each need to increase their respective success rates to approximately 5 playoff series appearances in 14 years, which means reaching the playoffs at least every third year. In order to attract fans in the $p=0.25$ category, Florida must increase its success rate to one 
of the following: 10 series appearances and 4 series wins in 14 years (reaching the playoffs six times); 12 series appearances and 3 series wins in 14 years (reaching the playoffs 9 times); 14 series appearances and 2 series wins in 14 years (reaching the playoffs 12 times); or 16 series appearances and one series win in 14 years (reaching the playoffs every year). Columbus and Winnipeg, however, need increase their respective success rates to, for example, 9 series appearances and 3 series wins in 14 years (reaching the playoffs six times), or 11 series appearances and 2 series wins in 14 years (reaching the playoffs 9 times).

Given that success rates have a greater impact than location on a team's ability to attract fans, it is likely that many cities in North America are capable of financially sustaining a successful NHL team. However, as evidenced by the outliers in Fig. 5, a high locational quality is advantageous, as it lowers the success rate needed to ensure a team's financial viability. It is not a given that a city with a low locational quality will be unable to support an NHL team; however, a high locational quality is an advantage to a new team as it works to attract fans in the team's first years. Since many expansion or relocation teams struggle on-ice for the first several years, this advantage may be quite significant in the long run. ${ }^{4}$

\section{Potential expansion sites}

\section{Current NHL expansion considerations - Québec City and Las Vegas}

Las Vegas and Québec City are involved in the current NHL expansion considerations [20]. In terms of locational quality, Québec City, at 122.1, is just higher than the league average of 118.1, and on par with Boston and Winnipeg, both at approximately 121.9. Las Vegas' locational quality is much lower; at only 90.9, it is closest to Anaheim at 90.2, and is higher than the cities of only three other current teams: San Jose at 72.3, Raleigh at 81.5, and Nashville at 84.4 (See Table 3).

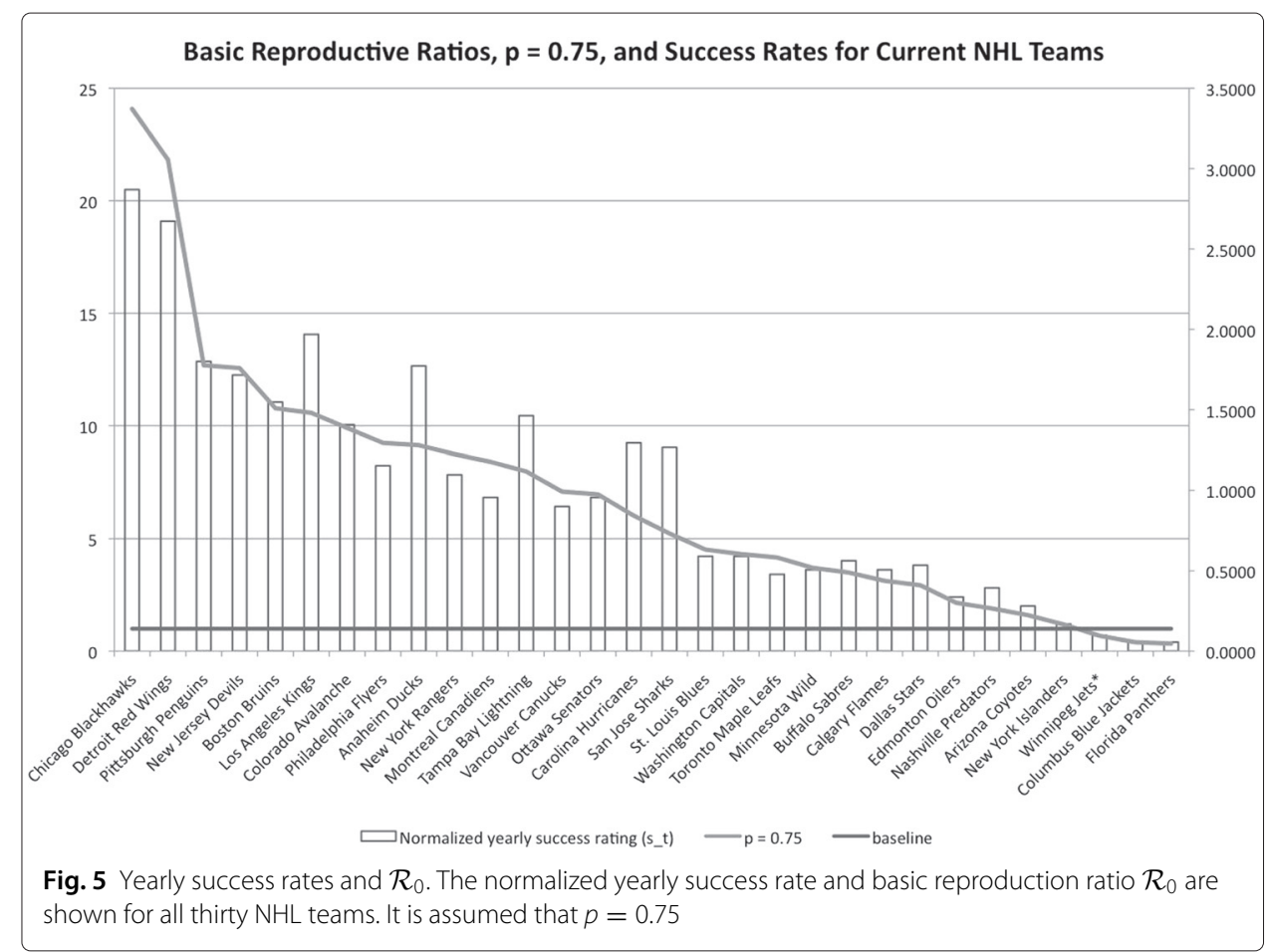




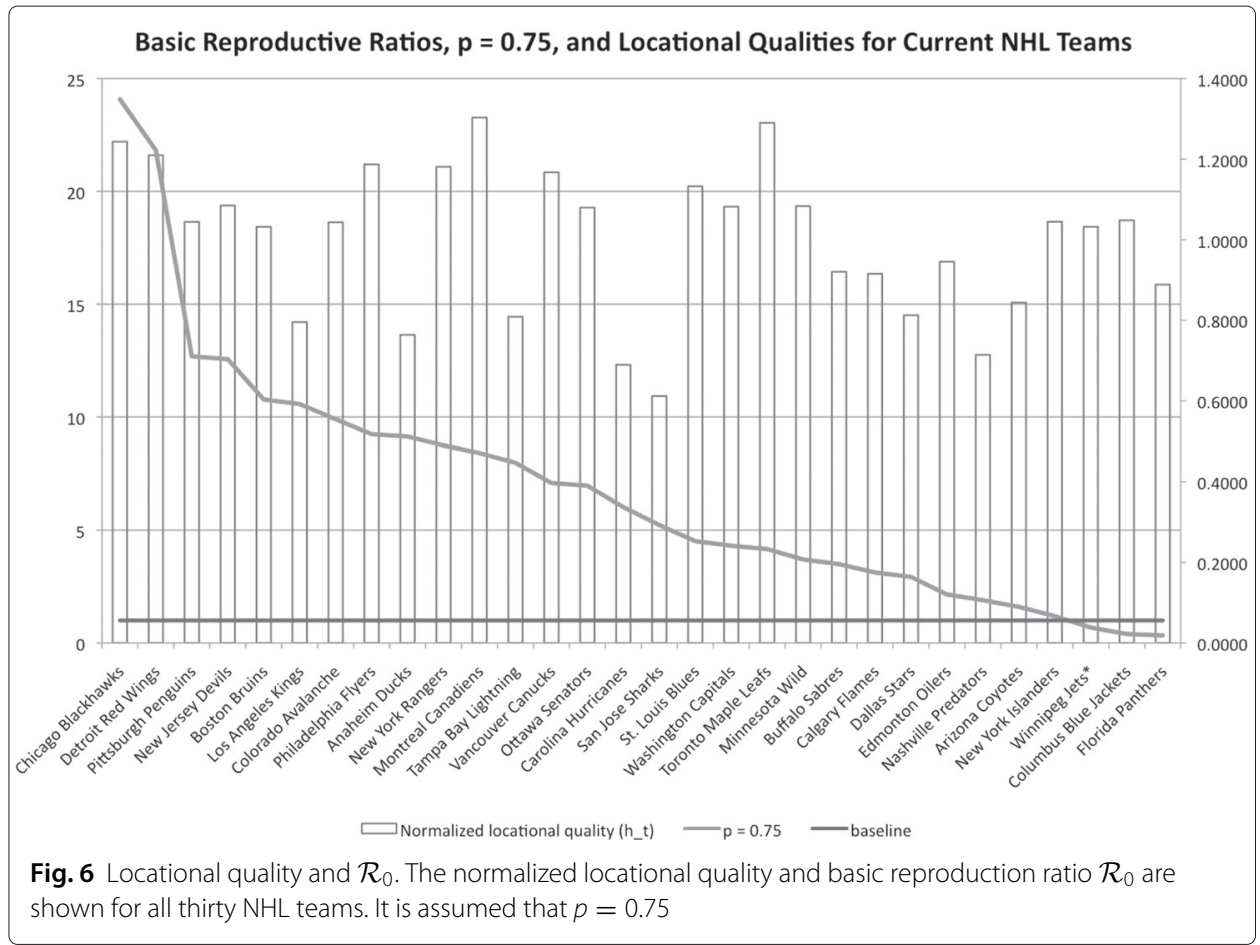

Table 5 lists the minimum success rates required to attain an $R_{0}>1$ for potential expansion sites.

For a team in Québec City to be viable, it would need to have similar success rates to Boston $\left(\mathcal{R}_{0}>1\right.$ when $\left.p=0.25,0.75\right)$, Colorado $\left(\mathcal{R}_{0}>1\right.$ when $\left.p=0.25,0.75\right)$ or the New York Islanders $\left(\mathcal{R}_{0}>1\right.$ when $\left.p=0.75\right)$. We note that expansion teams, in general, do not have very good success rates [14] (see Footnote 4 above), so a success rate similar to the New York Islanders could be expected, but a large $p$ is needed for viability. Québec City previously hosted the Nordiques in the NHL from 1979 until the team relocated to Denver, Colorado in 1995. Many inhabitants of the city have not forgotten their old team and would be eager to support a new Nordiques team if the league allows it [1]. It is also expected that season tickets would sell out quickly in Québec City, similar to what occurred in Winnipeg when the Jets returned to that city in 2011 [33]. Thus, it is not unreasonable to believe that $p$ could be high, and thus, a team in Québec City could thrive. Drawbacks that must be considered include the low Canadian dollar [27] and the relatively small size of the city [25].

Table 5 Minimum success rates required to attain a basic reproduction ratio greater than one for a theoretical team located in one of the listed cities

\begin{tabular}{lllll}
\hline & \multicolumn{4}{l}{ Minimum $s_{t}$ to attain $\mathcal{R}_{0}>1$ for $p=0.05, p=0.25,0.75$} \\
Team location & $H_{t}$ & $s_{t}, p=0.05$ & $s_{t}, p=0.25$ & $s_{t}, p=0.75$ \\
\hline Hamilton & 129.5652 & 2.0260 & 0.4052 & 0.1351 \\
Kansas city & 127.7109 & 2.0554 & 0.4111 & 0.1370 \\
Las Vegas & 90.9040 & 2.8876 & 0.5775 & 0.1925 \\
Québec city & 122.0949 & 2.1499 & 0.4300 & 0.1433 \\
Seattle & 81.9726 & 3.2022 & 0.6404 & 0.2135 \\
\hline
\end{tabular}


In Las Vegas, because of the city's much lower locational quality, a team would need to make 7 series appearances in 14 years for a $p=0.75$. This means that the team must reach the postseason every second year. In the $p=0.25$ category, a team in Las Vegas would need 11 series appearances and 5 series wins in order to ensure that $\mathcal{R}_{0}$ is greater than 1. Again, citing the low expected success rates of expansion teams [14], these success ratings are very unlikely.

Bill Foley, who leads the group in Las Vegas, successfully ran a season ticket drive that secured more than 13200 deposits for season tickets [30]. Interestingly, Las Vegas does not currently host a professional sports team from any of the major sports leagues [30], ${ }^{5}$ which may help a potential NHL team gain fans in the city. Its status as a popular tourist destination means that the many visitors from colder climates can be expected to purchase single-game tickets, as is already the case among 'snowbirds' ${ }^{6}$ who visit Miami and Tampa in Florida [12]. The main drawback to putting a team in Las Vegas is the hot, dry climate, which is not conducive to ice hockey. As a result, there is little local interest in the sport, as evidenced by the low participation levels in amateur hockey in the state of Nevada [29].

\section{Other potential expansion cities - Hamilton, Kansas City and Seattle}

Although applications for teams in Kansas City, Seattle, and Hamilton - or the Greater Toronto Area - were not submitted for consideration in the current expansion process, these cities remain interesting as possible future sites for an expansion or relocation team. Hamilton, approximately 60 kilometres outside of Toronto, has the highest locational quality of the three; at 129.6, its locational quality is higher than those of all current Canadian teams except Montreal, Toronto, and Vancouver. Kansas City is not far behind at 127.7, which is on a par with Newark, NJ at 128.1, Minneapolis-St. Paul, MN at 128.0, Washington, D.C. at 127.8 and Ottawa at 127.5. Seattle's locational quality is low at 82.0, higher than only two current teams: Raleigh, NC and San Jose.

Hamilton and Kansas City have higher locational qualities than Québec City; thus, a team in each of these cities would need a slightly lower success rate than Boston, Colorado, and the New York Islanders: for potential fans in the $p=0.25$ category, teams in these cities would only need 8 series appearances and 3 series wins, or 10 series appearances and 2 series wins, to reach $\mathcal{R}_{0}>1$.

Based on its high locational quality, Kansas City could be an excellent place in which to put an expansion team. No potential ownership group completed an application in the current NHL expansion application process, but this does not rule it out as a potential location for an expansion or relocation team in the future.

Based on its locational quality, Hamilton seems to be an excellent place to put a new NHL team; however, its situation is complicated. Due to its proximity to both Toronto and Buffalo, a team in Hamilton could potentially 'steal' fans and revenue from either of those two cities, which might affect the viability of those teams. This proximity would not be expected to harm the Toronto Maple Leafs' viability since the Leafs remain the most financially successful team in the league despite reaching the playoffs only once in the last ten years $[14,16,24]$; however, the less successful Buffalo Sabres could potentially experience significant damage.

In order to gain more insight into Hamilton's situation, we looked at the situation in New York City, where three teams - the New York Rangers in Manhattan, the New 
York Islanders in Long Island, and the New Jersey Devils in Newark - are located within metropolitan New York City. In order to divide up the population of metro New York for our calculations, we looked at how the city's 2014 hockey revenue was split between the three teams. The revenue split was as follows: the Rangers had $53 \%$, the Islanders, $20 \%$, and the Devils, $27 \%$, of the city's hockey revenue. While the situation in TorontoHamilton-Buffalo is not identical due to a greater distance between the teams, the revenue split in New York City provides insight into whether a team in Hamilton would be financially viable.

It should be noted that this comparison rests on two assumptions: first, that Buffalo's revenue would not decrease; and second, that a team in Hamilton would bring in new revenue. If a team in Hamilton has a $20 \%$ share of the revenue in the region, similar to the Islanders, then such a team can expect a revenue of $\$ 73.25$ million, which is significantly lower than any current team. Since several current teams struggle even with higher revenues, such a low amount does not point to financial viability. However, if a team in Hamilton has a $27 \%$ share of the region's revenue, it can expect a much more viable revenue of $\$ 108.37$ million. If we relax the second assumption and allow the team in Hamilton to rely on revenue 'stolen' from Toronto and Buffalo, it will not be viable based on the above revenue split, and, furthermore, will greatly damage the Buffalo Sabres' financial viability.

The NHL may be hesitant to approve a team in Hamilton because of the potential danger to the viability of the Buffalo Sabres, who have not reached the postseason since 2011. Unless the Sabres start to reach the playoffs more regularly, thereby stabilizing their fanbase and securing the team's financial health, the NHL is unlikely to approve a team in Hamilton in the near future.

An expansion team in Seattle would need at least 8 series appearances in 14 years for $p=0.75$ and at least 13 appearances and 5 wins for $p=0.25$ for the team to be viable, even more than a team in Las Vegas. Thus, Seattle might not be a good place in which to put an expansion team. We note, however, that Seattle previously hosted a professional ice hockey team, the Seattle Metropolitans, which played in the Pacific Coast Hockey League from 1915-24 [14]. This history, along with its proximity to the Canadian border, may have a positive effect on the success rate needed in this city.

\section{Conclusions}

The applications for expansion teams Québec City, Québec, and Las Vegas, Nevada by potential ownership groups have passed the first round of the application process (started by the NHL in June 2015), and are currently being evaluated by the league. Our study suggests that NHL expansion in Québec City would be viable, but that expansion to Las Vegas would be very risky. Our study also found that other North American cities that have shown interest in hosting NHL teams could be worthy of consideration, in particular Hamilton and Kansas City. We conclude that Québec City represents a viable option for NHL expansion, with Hamilton and Kansas City deserving consideration as well.

Our results are supported by a locational quality and success rating evaluation of all current NHL teams. The locational quality was determined using the population, GDP per capita, and mean winter temperature of all NHL cities and potential expansion cities. The success ratings of all current NHL teams were determined from Stanley Cup playoff and championship data for the years 2001-15. Given the locational quality of the potential 
NHL expansion cities, we then determined the success rating that an expansion team in each city would need to achieve in order to attract new fans.

Model results show that most current NHL teams can expect to have trouble gaining fans with little connection to hockey (see Table 4 and Fig. 4). Among those susceptible individuals in the category $p=0.25$, some fanbases could grow but many others would not, including some Canadian teams. Stability analysis of the model equilibria shows that the existence of chronically infected fans will enable growth in fan allegiance; however, for this growth to occur, susceptible individuals must have exposure to devoted fans. Calculation of a threshold of devoted fans needed to guarantee team financial stability is a course for future work.

In our analysis, we included a parameter that involved average winter temperature as a variable in our evaluation of locational quality to reflect 'fan interest' in the sport. We note here that involvement in amateur hockey and local leagues may be a better indication of hockey interest. Data compilation on participation rates in ice hockey, roller hockey, and ball hockey leagues is a course for future work.

Along a similar argument to that above, fans are more likely to be found in places where a particular sport is of interest. We suggest that expansion of the NHL to a particular geographic location could be preceded by NHL sponsorship or investment in hockey activities at the local level. This could involve sponsorship of house leagues, encouraging NHL player involvement in community activities, or even financial bursaries to renovate or build hockey facilities.

Finally, our analysis did not consider future expansion in the Greater Toronto Area (GTA). Considering that Los Angeles and New York City each support more than one NHL team, perhaps metropolitan Toronto is capable of supporting a second team as well. Toronto has a high locational quality that is second in the league, behind only Montreal, and at 6 million, it has the largest metropolitan population in Canada. Los Angeles hosts two teams, thus a comparison of Toronto to Los Angeles could be warranted. Revenue in Los Angeles for 2014 was split $58-42 \%$ between the Kings and Ducks. If putting a new team in the GTA does not bring in new revenue but rather splits the Toronto Maple Leafs' current revenue of $\$ 190$ million - with the Leafs retaining the larger share - the new team would have a revenue of only $\$ 79.80$ million. Given that the Arizona Coyotes had the lowest 2014 revenue in the league at $\$ 80$ million and are known to be struggling financially [24, 28], $\$ 79.8$ million may not be a viable revenue for a new team. This is a very simple analysis, however. Consideration must also be given to the cost of seasons tickets, individual tickets sales, and the seating capacity of the Maple Leaf arena, all factors that limit the spending habits of Maple Leaf fans. Thus, it could be expected that a new NHL team in the GTA could bring in new revenue. A game theoretic analysis of fan allegiance and merchandise sales would be informative here, and is a course for future work.

\section{Endnotes}

${ }^{1}$ Two teams, the Minnesota Wild and the Columbus Blue Jackets, joined the league for the 2000-01 season, bringing the total number of teams in the league to 30 , the current number.

${ }^{2}$ Since the entire 2004-05 season was lost to a labour dispute, or 'lockout', this timeframe includes only 14 seasons. 
${ }^{3}$ A term commonly used to refer to the six teams in the NHL from 1943-1967: Boston, Chicago, Detroit, Montreal, New York Rangers, Toronto.

${ }^{4}$ None of the nine expansion teams added to the NHL since 1991 reached the playoffs in its first year in the league; only one team, the Carolina Hurricanes, reached the playoffs in its second year; and two other teams, the San Jose Sharks and the Minnesota Wild, reached the playoffs in their third year [14].

${ }^{5}$ The major sports leagues in North America, often referred to as the 'Big Four', include the NHL, the National Football League, the National Basketball Association, and Major League Baseball.

${ }^{6}$ Canadians who spend the winter months in Florida are often referred to as 'snowbirds.'

\section{Acknowledgments}

The authors thank Jon Forde for interesting discussions. JMH is funded by NSERC.

\section{Authors' contributions}

$J \mathrm{~L}, \mathrm{AC}$ and $J \mathrm{MH}$ particpated in the development of the model, analysis and interpretation of results, and in the writing of the manuscript. All authors read and approved the final manuscript.

\section{Competing interests}

The author declares that that they have no competing interests.

Received: 27 April 2016 Accepted: 29 August 2016

Published online: 04 October 2016

\section{References}

1. Associated Press (2015) Quebec City group makes NHL expansion pitch Tuesday. http://www.cbc.ca/news/canada/ montreal/quebec-city-nhl-presentation-1.3248049. Web. Accessed Apr 2016

2. Badenhausen K (2011) The NFL signs TV deals worth $\$ 27$ billion. www.forbes.com/sites/kurtbadenhausen/2011/12/ 14/the-nfl-signs-tv-deals-worth-26-billion/\#12a158252a67. Web. Accessed Apr 2016

3. Boylen R (2014) Looking at six potential NHL expansion/relocation destinations, from Las Vegas to Hamilton. The Hockey News, http://www.thehockeynews.com/news/article/looking-at-six-potential-nhl-expansionrelocationdestinations-from-las-vegas-to-hamilton. Web

4. Chidley-Hill J (2015) Jays chase Leafs on social media, followers drawn by post-season run. https://www.thestar.com/ sports/bluejays/2015/10/14/jays-chase-leafs-on-social-media-followers-drawn-by-post-season-run.html. Web

5. Condor B (2011) NHL, NBC sign record-setting 10-year TV deal. https://www.nhl.com/news/nhl-nbc-sign-recordsetting-10-year-tv-deal/c-560238. Web. Accessed Apr 2016

6. Current Results Nexus. Weather averages. www.CurrentResults.com. Web. Accessed Apr 2016

7. ESPN (2011) NHL Attendance Report - 2010-11. www.ESPN.com. Web. Accessed Apr 2016

8. ESPN (2012) NHL Attendance Report - 2011-12. www.ESPN.com. Web. Accessed Apr 2016

9. ESPN (2013) NHL Attendance Report - 2012-13. www.ESPN.com. Web. Accessed Apr 2016

10. ESPN (2014) NHL Attendance Report - 2013-14. www.ESPN.com. Web. Accessed Apr 2016

11. ESPN (2015) NHL Attendance Report - 2014-15. www.ESPN.com. Web. Accessed Apr 2016

12. Fialkov H (2015) Barkov lifts surging Panthers past Canadiens 3-1 and into first place. www.Sun-Sentinel.com. Web. Accessed Apr 2016

13. Forum Research (2014) The Forum Poll: One half of Canadians are NHL fans. http://poll.forumresearch.com/post/ 162/one-half-of-canadians-are-nhl-fans/. Web

14. HockeyDB.com (2015) National Hockey League history and statistics. http://www.hockeydb.com/ihdb/stats/ leagues/141.html. Web

15. James JD, Kolbe RH (2000) An identification and examination of influences that shape the creation of a professional team fan. Int J Sports Mark Sponsorship 2(1):14-28. Accessed Apr 2016

16. Johnston M (2015) Second Toronto-area NHL team will have to wait. http://www.sportsnet.ca/hockey/nhl/secondtoronto-area-nhl-team-will-have-to-wait/. Web. Accessed Apr 2016

17. Jones JCH (1984) Winners, Losers and Hosers: Demand and survival in the National Hockey League. Atl Econ J 12(3):54-63

18. Jones JCH, Ferguson DG (1988) Location and survival in the National Hockey League. J Ind Econ 36(4):443-457

19. NHL.com (2014) Rogers deal changes viewing landscape dramatically. https://www.nhl.com/news/rogers-dealchanges-viewing-landscape-dramatically/c-733428. Web

20. NHL Public Relations (2015) Update on NHL expansion application process. https://www.nhl.com/news/update-onnhl-expansion-application-process/c-775295. Web. Accessed Apr 2016

21. Ozanian M (2011) The business of hockey: Team values hit all-time high. http://www.forbes.com/sites/mikeozanian/ 2011/11/30/the-business-of-hockey/\#2369cd201310. Web. Accessed Apr 2016

22. Ozanian M (2012) NHL team values 2012: Toronto Maple Leafs are first hockey team worth $\$ 1$ billion. http://www. forbes.com/sites/mikeozanian/2012/11/28/nhl-team-values-2012-maple-leafs-first-hockey-team-worth-1-billion/\# 67faa2ae1c36. Web. Accessed Apr 2016 
23. Ozanian M (2013) The NHL's most valuable teams. http://www.forbes.com/sites/mikeozanian/2013/11/25/the-nhlsmost-valuable-teams/\#54db4e073d95. Web. Accessed Apr 2016

24. Ozanian M (2014) The most valuable teams in the NHL. http://www.forbes.com/sites/mikeozanian/2014/11/25/themost-valuable-teams-in-the-nhl/\#4a1c01c57e5b. Web

25. Parilla J, Trujillo JL, Berube A (2014) Global Metro Monitor. Technical report, Brookings Institution, Washington, D. C

26. Robillard A (2015) Harper says 'no better place' than Quebec City for NHL expansion team. http://www. theglobeandmail.com/sports/hockey/harper-says-no-better-place-than-quebec-city-for-nhl-expansion-team/ article25113047/. Web. Accessed Apr 2016

27. Rosen D (2016) Bettman says NHL expansion process is ongoing. https://www.nhl.com/news/bettman-says-nhlexpansion-process-is-ongoing/c-800364. Web. Accessed Apr 2016

28. Shoalts D (2014) Arizona Coyotes owners pan for gold in river of red ink. http://www.theglobeandmail.com/sports/ hockey/arizona-coyotes-owners-pan-for-gold-in-river-of-red-ink/article21489565/. Web. Accessed Apr 2016

29. USA Hockey (2015) 2014-2015 Season Final Registration Reports. Technical report, USA Hockey

30. Wawrow J (2015) Las Vegas, Quebec City enter final phase of NHL expansion process. http://www.theglobeandmail. $\mathrm{com} /$ sports/hockey/las-vegas-quebec-city-enter-final-phase-of-nhl-expansion-process/article26062487/. Web. Accessed Apr 2016

31. Whyno S (2014) Las Vegas season-ticket drive raises more questions about NHL expansion. http://www. theglobeandmail.com/sports/hockey/las-vegas-season-ticket-drive-raises-more-questions-about-nhl-expansion/ article22010858/. Web. Accessed Apr 2016

32. Whyno S (2015) NHL board approves opening formal expansion process. https://www.thestar.com/sports/hockey/ 2015/06/24/nhl-board-set-to-approve-opening-formal-expansion-process.html. Web. Accessed Apr 2016

33. Whyno S (2015) Winnipeg's 'Drive to 13,000' is gold standard for Las Vegas. https://www.nhl.com/news/winnipegsdrive-to-13000-is-gold-standard-for-las-vegas-season-ticket-drive/c-752834. Web

34. Woolsey G (2008) Sales pitch for NHL expansion in Canada. https://www.thestar.com/opinion/columnists/2008/01/ 21/sales_pitch_for_nhl_expansion_in_canada.html. Web. Accessed Apr 2016

\section{Submit your manuscript to a SpringerOpen ${ }^{\odot}$ journal and benefit from:}

- Convenient online submission

- Rigorous peer review

- Immediate publication on acceptance

- Open access: articles freely available online

- High visibility within the field

- Retaining the copyright to your article

Submit your next manuscript at $\gg$ springeropen.com 